\title{
Fluoro-edenite induces fibulin-3 overexpression in non-malignant human mesothelial cells
}

\author{
VENERANDO RAPISARDA ${ }^{1 *}$, ROSSELLA SALEMI $^{2 *}$, ANDREA MARCONI $^{1}$, CARLA LORETO $^{3}$, \\ ADRIANA C. GRAZIANO ${ }^{4}$, VENERA CARDILE ${ }^{4}$, MARIA S. BASILE ${ }^{2}$, SAVERIO CANDIDO $^{2}$, \\ LUCA FALZONE $^{2}$, DEMETRIOS A. SPANDIDOS ${ }^{5}, \operatorname{CONCETTINA~FENGA~}^{6 * *}$ and MASSIMO LIBRA ${ }^{2 * *}$ \\ ${ }^{1}$ Section of Occupational Medicine, Department of Clinical and Experimental Medicine, ${ }^{2}$ Section of General and Clinical \\ Pathology and Oncology, Department of Biomedical and Biotechnological Sciences, ${ }^{3}$ Section of Human Anatomy \\ and Histology, and ${ }^{4}$ Section of Physiology, Department of Biomedical and Biotechnological Sciences, University of Catania, \\ I-95124 Catania, Italy; ${ }^{5}$ Department of Virology, Faculty of Medicine, University of Crete, 71003 Heraklion, \\ Crete, Greece; ${ }^{6}$ Section of Occupational Medicine, Department of the Environment, Safety, \\ Territory, Food and Health Sciences, University of Messina, I-98125 Messina, Italy
}

Received May 6, 2016; Accepted August 18, 2016

DOI: $10.3892 / \mathrm{ol} .2016 .5051$

\begin{abstract}
Exposure to asbestos is associated with the development of mesothelioma. In addition to asbestos, other fibers have been identified as risk factors for malignant and non-malignant diseases of the lungs. Among these, fluoro-edenite (FE) was found in patients from Biancavilla (Sicily, Italy) with pleural and lung disease, suggesting its role for tumor expansion. In this context, the identification of early biomarkers useful for the diagnosis of cancer is mandatory. Fibulin-3 represents an important marker for the diagnosis of mesothelioma. However, it remains to be determined whether it is directly associated with exposure to asbestos-like fibers. In the present study, peripheral blood levels of fibulin-3 from 40 asbestos-exposed workers were compared with those detected in 27 street cleaners from Biancavilla. Intriguingly, the results showed that fibulin-3 levels were higher in the group of street cleaners compared with those of the asbestos-exposed workers, suggesting that these workers used the personal protective equipment according to the current regulations. These data suggest that subjects exposed to FE should be monitored for the risk of mesothelioma. FE and volcanic particulates are probably contained within dust inhaled by street cleaners
\end{abstract}

Correspondence to: Professor Massimo Libra, Section of General and Clinical Pathology and Oncology, Department of Biomedical and Biotechnological Sciences, University of Catania, Via Androne 83, I-95124 Catania, Italy

E-mail: mlibra@unict.it

"Contributed equally; **Joint senior authorship

Key words: fluoro-edentite, mesothelioma, lung cancer, asbestos, fibulin-3, stathmin from Biancavilla during their work activities. Based on these criteria, in this study, such fibers were used to treat mesothelial cells (MeT5A) in order to verify whether fibulin-3 levels are affected by these treatments. The results showed that only treatment with FE was associated with fibulin-3 overexpression at both the transcript and protein levels. It was previously demonstrated that mesothelial cells exhibited low levels of p27 following treatment with FE. Notably, p27 downregulation is associated with stathmin upregulation in cancer, conferring an aggressive phenotype of tumor cells. This observation prompted us to perform a computational evaluation demonstrating the activation of stathmin in lung cancer in patients exposed to asbestos. Overall, it can be speculated that both fibulin-3 and stathmin overexpression may be associated with the malignant transformation of mesothelial cells following exposure to asbestos-like fibers.

\section{Introduction}

Asbestos has been widely used in many industrial contexts for its extraordinary thermal insulation properties. Over the past years, millions of tons of asbestos have been processed worldwide. The most common asbestos used is the chrysotile (white asbestos), followed by amphibolic asbestos (blue and brown asbestos). However, their toxic effects have been known for 50 years (1).

It is already known that asbestos inhalation can induce the development of mesothelioma and several other cancer types, included that of the lung. Specifically, the risk of developing lung cancer has been suggested to be related to the cumulative exposure to asbestos, with an estimated increase in risk of $1 \%$ for each fiber/ml-year of exposure (2). It has also been observed that exposure to asbestos may be associated with nonneoplastic diseases, such as asbestosis and pleural fibrosis (3). The interval between first exposure and the development of mesothelioma ranges from 20 to 60 years (4). The highest worldwide incidence is estimated occur in the year 2020 (5). 
Individuals who are at risk are those who have previously worked in shipbuilding industries, railway construction companies and asbestos-cement industries; however, due to the spread of asbestos shipyards, home improvements and many other types of uncontrolled construction work, a larger number of cases have been identified among building craftsmen exposed accidentally and often unknowingly. Moreover, unwitting victims of asbestos are the wives and children of workers who carry home asbestos dust on their clothes. The difficulty of removing asbestos already in place represents an additional risk for the development of mesothelioma and lung cancer $(2,6)$.

Health surveillance in workers exposed to asbestos is focused on the early detection of the major diseases related to asbestos (7). Unfortunately, the health surveillance protocols adopted for workers exposed to asbestos do not meet the requirements of sensitivity and specificity required to ensure early diagnosis (8). Additionally, apart from asbestos fibers, it has been demonstrated that other fibers, such as fluoroedenite (FE), may have toxic effects (9).

Therefore, there is an urgent need to identify novel markers useful for the early diagnosis of asbestos and asbestos-like fibers-associated diseases. Although it has been demonstrated that fibulin-3 is an important marker used for the diagnosis of mesothelioma (10), its role in the early stage of the disease is still under debate.

High circulating levels of fibulin-3 have been observed in street cleaners from Biancavilla (Sicily, Italy), which are at high risk of FE exposure, when comparing their pleural plaques with those of a non-exposed control group (11-13). However, if such an overexpression is due to the exposure of asbestos-like fibers or to other environmental factors, such as volcanic particulates, remains to be further clarified.

On the basis of these criteria, in the present study, we analyzed circulating levels of fibulin-3 in individuals exposed to asbestos and compared with them with those previously detected in workers exposed to FE. Furthermore, in vitro experiments using mesothelial cells (Met5A) were performed to determine whether the expression of fibulin-3 correlates with the exposure to asbestos-like fibers and/or other particulates.

\section{Materials and methods}

Subjects. The subjects enrolled in the present study included 40 workers exposed to asbestos fibers, including 30 removal and disposal workers and 10 coating workers, employed in old pipeline maintenance. Ten healthy subjects were also included as controls. The subjects and healthy controls included in this study were recruited at the Occupational Medicine Unit, School of Medicine, University of Catania, Catania, Italy. They comprised both categories of workers, those exposed to asbestos fibers (cases) and those without such exposure working in different places (healthy subjects or controls). All study participants provided a written informed consent. The study was approved by the University of Catania Ethics Committee.

Information on occupational history, socio-demographic indicators, smoking habits and clinical history were collected using validated questionnaires. Briefly, all subjects (workers) were male, with a mean age of 52 years; 30 out of 40 were smokers; the mean duration of exposure to asbestos was 14 years. All healthy subjects were male with a mean age of 50 years and all of them were smokers. The participants underwent blood testing, spirometry, physical examination and chest high-resolution computed tomography (HRCT).

Blood samples were collected into EDTA plasma tubes and processed within $2 \mathrm{~h}$. The samples were centrifuged at $950 \times \mathrm{g}$ for $10 \mathrm{~min}$ and the supernatant was aliquoted and stored at $-80^{\circ} \mathrm{C}$ until analysis.

Enzyme-linked immunosorbent assay (ELISA). Fibulin-3 plasma levels were determined in the 40 cases and in 10 controls in duplicate using a human EGF-containing fibulin-like extracellular matrix protein 1 (EFEMP1) ELISA kit (Cusabio Biotech Co., Ltd., College Park, MD, USA) according to the manufacturer's instructions. Plasma samples were diluted and the immunoassay was carried out according to the manufacturer's instructions. Marker concentrations for each sample were calculated from the standard curve. All tests were assayed in duplicate. A subset of samples was assayed 4 times in each ELISA plate for quality control. No significant cross-reactivity to or interference with various proteins was observed. The optical density was measured at $450 \mathrm{~nm}$ using a microplate reader (Tecan ELISA Reader; Tecan Group Ltd., Männedorf, Switzerland). The results were compared with those obtained from the 27 street cleaners exposed to carcinogenic fibers analyzed in our previous study (11).

Cell culture and treatment. The non-malignant transformed human pleural mesothelial cell line (Met-5A) was obtained from the American Type Culture Collection (ATCC; Manassas, VA, USA) and cultured in RPMI-1640 medium, supplemented with $10 \%$ fetal bovine serum, $1 \%$ penicillin/streptomycin (all from Lonza, Walkersville, MD, USA) and incubated at $37^{\circ} \mathrm{C}$ in humidified atmosphere with $5 \% \mathrm{CO}_{2}$.

The cells were plated at a density of 120,000 cells/ well in a 6-well dish in a final volume of $2 \mathrm{ml}$ per well, and exposed to various concentrations of FE and A, B, C and D volcanic particulates $(10,50$ and $100 \mu \mathrm{g} / \mathrm{ml})$ for $72 \mathrm{~h}$. MeT5A cells grown in normal medium were used as controls. Subsequently the cells were deprived of culture medium and washed in phosphate-buffered saline (PBS), then collected in tubes and centrifuged at $250 \mathrm{xg}$ for $5 \mathrm{~min}$ at $4^{\circ} \mathrm{C}$. The pellets thus obtained were stored at $-80^{\circ} \mathrm{C}$ before being used for protein and RNA extraction. All treatments were performed in triplicate.

FE fibers were collected in the area of Biancavilla (Sicily) and then characterized. The volcanic particulates [A (basalt residues), B (volcanic ash), C (mixed basalt and cement) and D (cement)], were collected in different areas of Mount Etna (Sicily, Italy) and underwent physical and chemical characterizations, as previously described (14). All particles were suspended in RPMI-1640 medium to yield stock solutions.

Reverse transcription-quantitative (real-time) $P C R$ $(R T-q P C R)$. Total RNA was isolated from the cell pellets using an extraction kit (PureLink RNA mini kit; Ambion/ Life Technologies, Carlsbad, CA, USA) according to the manufacturer's instructions. First-strand cDNA was reverse transcribed with $1 \mu \mathrm{g}$ of total RNA. The resultant cDNA was then used for quantitative PCR (qPCR) reactions, which were 
performed using the Applied Biosystems 7300 Real-Time PCR system (Applied Biosystems, Foster City, CA, USA).

The fibulin-3 primer sequences were as follows: 5'-CGA GGGGAGCAGTGCGTAGACATAG-3' (sense) and 5'-CTT CACAGTTGAGCCTGTCACTGCT-3' (antisense). The housekeeping gene, phosphoglycerate kinase 1 (PGK1), was used as an internal control for normalization of the results. The PGK1 primer sequences were as follows: 5'-TTAAAGGG AAGCGGGTCGTT-3' (sense) and 5'-CAGGCATGGGCA CACCAT-3' (antisense).

The amplification of fibulin-3 and PGK1 was performed with 1 cycle at $95^{\circ} \mathrm{C}$ for $10 \mathrm{~min}$, and 40 cycles at $95^{\circ} \mathrm{C}$ for $15 \mathrm{sec}$ and $60^{\circ} \mathrm{C}$ for $1 \mathrm{~min}$. The calculation of the relative expression of each transcript was performed using the $2^{-\Delta \Delta \mathrm{Ct}}$ method.

Western blot analysis. The cells were lysed in NP-40 cell lysis buffer (50 mM Tris pH 7.4, $250 \mathrm{mM} \mathrm{NaCl,} 5 \mathrm{mM}$ EDTA, $50 \mathrm{mM} \mathrm{NaF}, 1 \mathrm{mM} \mathrm{Na} \mathrm{VO}_{4}, 1 \%$ Nonidet P-40, $0.02 \% \mathrm{NaN}_{3}$ ) containing a protease inhibitor cocktail (Sigma, St. Louis, MO, USA). The extracted protein amounts were quantified using the Quick Start ${ }^{\mathrm{TM}}$ Bradford 1X Dye Reagent assay (Bio-Rad Laboratories, Inc., Hercules, CA, USA). Equivalent amounts of protein $(40 \mu \mathrm{g})$ were separated using Mini Protean TGX Precast Gels (Bio-Rad Laboratories, Inc.; 4-15\%) and transferred onto a PVDF/nitrocellulose membrane (Bio-Rad Laboratories, Inc.). Western blot analysis was performed using the following primary antibodies: EFEMP1 (PA526104) (Thermo Fisher Scientific, Waltham, MA, USA) and $\beta$-tubulin (ab15568) (Abcam, Cambridge, UK). The western blot analysis signal was detected using the ChemiDoc Touch Imaging system (Bio-Rad Laboratories, Inc.). The densitometry of the western blot analysis results was measured using Image J software (National Institutes of Health, Bethesda, MD, USA).

Computational analysis of stathmin 1. To determine whether stathmin 1 overexpression is associated with exposure to asbestos, datasets of gene expression profiling available on the Gene Expression Omnibus (GEO) dataset (www.ncbi.nlm.nih. gov/geo/) were analyzed. Among all publically available GEO datasets, only those containing lung cancer or mesothelioma samples with stathmin 1 expression levels, clinical data relative to asbestos exposure were analyzed. Based on these criteria, only the GSE23822 dataset (15) was used for our analysis. This dataset includes 26 samples of lung cancer with confirmed asbestos exposure and 30 non-exposed samples.

No additional normalization procedure was applied. Differential analysis of stathmin 1 expression levels between the exposed and non-exposed groups was performed using the Student's t-test.

Statistical analysis. Statistical analysis of fibulin-3 expression in the plasma samples was performed using Kruskal-Wallis test. The analysis of the expression levels of EFEMP1 in the cells was obtained using the Student's t-test. A value of $\mathrm{p}<0.05$ (by a two-tailed test) was considered to indicate a statistically significant difference.

Odds ratios (OR) and the corresponding 95\% confidence intervals $(\mathrm{CI})$ were calculated by means of multiple logistic regression models including terms for gender, age and smoking

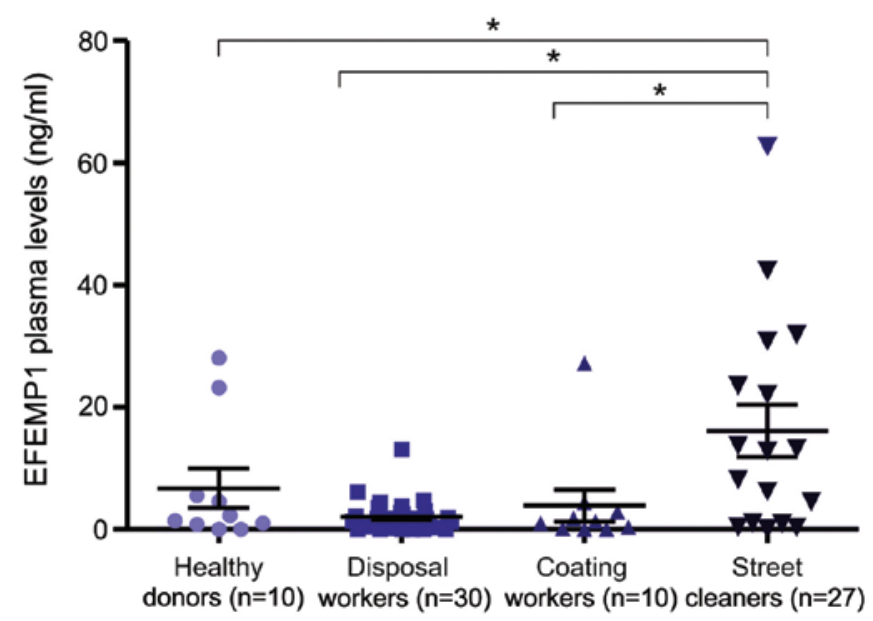

Figure 1. Circulating plasma levels of fibulin-3 in asbestos-exposed workers The data for the street cleaners (EFEMP-1, fibulin-3) were from a previous study (10). ${ }^{*} \mathrm{p}<0.05$

habits. The test for trend was based on the likelihood-ratio test between the models with and without linear terms for each variable of interest. The attributable risk percent values were computed as previously described (16). All statistical analyses were performed using SAS 9.2 statistical software (SAS Institute, Cary, NC, USA).

\section{Results}

Both groups of asbestos workers (disposal and coating) enrolled in this study did not report a diagnosis of mesothelioma or other pulmonary diseases (asbestosis and/ or pleural plaques); only 7 workers exhibited an allergy to pollen and/ or dust and 30 out of the 40 workers were smokers. The mean values (\% predicted) of the functional respiratory tests were within the normal range for both groups. Blood parameters were in the normal range (data not shown).

Analysis of fibulin-3 in workers. The median plasma levels of fibulin-3 were $1.51 \mathrm{ng} / \mathrm{ml}(0.46-3.978)$ and $1.73 \mathrm{ng} / \mathrm{ml}$ (1.012-3.59) in the removal/disposal and coating worker groups, respectively. These results were similar to those detected in the normal samples. However, statistical differences were observed when we compared these data with those obtained from the plasma of workers occupationally exposed to carcinogenic fibers previously analyzed (11) (Fig. 1). No association between fibulin-3 plasma levels and the duration of exposure to asbestos or the radiographic score was observed in these subjects. The fibulin-3 plasma levels were also not influenced by the age, gender or smoking habits of the subjects (data not shown).

Expression of fibulin-3 detected at the transcript and protein levels in MeT5A cells. The fibulin-3 protein and mRNA levels were evaluated in the MeT5A cells incubated with 10, 50 and $100 \mu \mathrm{g} / \mathrm{ml}$ of FE fibers and A, B, C and D volcanic particulates for $72 \mathrm{~h}$. As shown in Fig. 2A, a marked increase in fibulin-3 protein expression was observed in the MeT5A cells exposed to FE compared with the controls. However, the cells exposed to the A, B, C and D volcanic particulates did not 
A

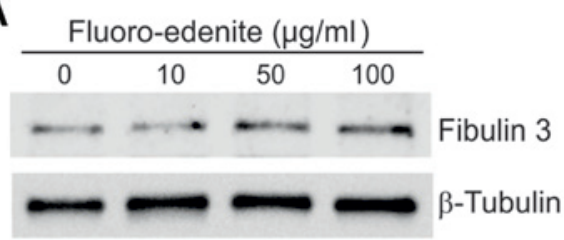

B

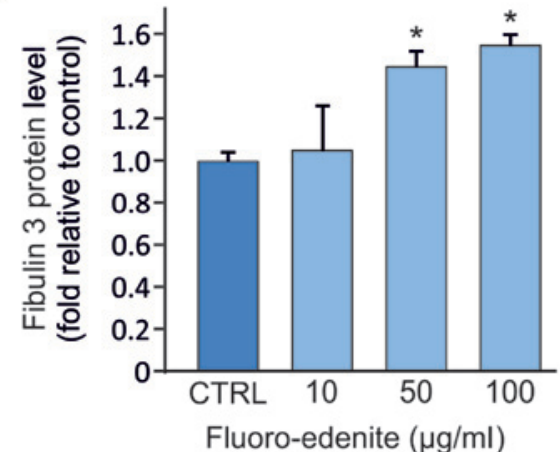

C

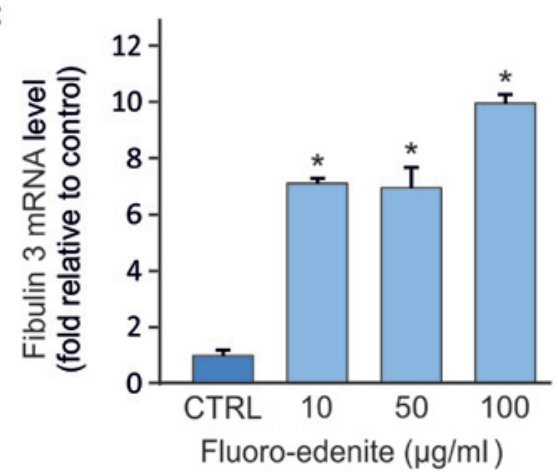

Figure 2. Fibulin-3 expression levels in mesothelial Met5A cell lines following exposure to various concentrations of fluoro-edenite fibers detected at the $(\mathrm{A}$ and $\mathrm{B})$ protein and $(\mathrm{C})$ transcript levels. ${ }^{*} \mathrm{p}<0.05$ compared to controls.

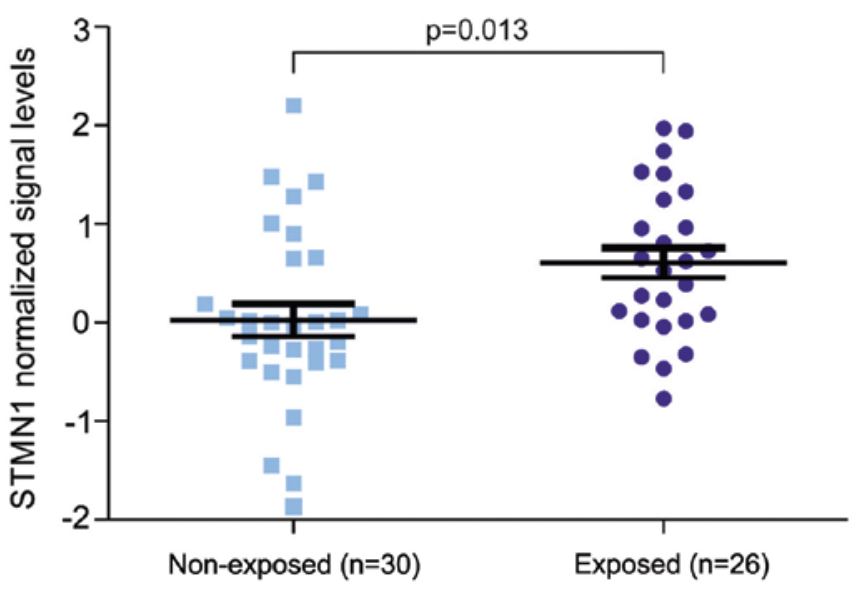

Figure 3. Differences of STMN1 transcript levels detected in lung cancers diagnosed in exposed and non-exposed to asbestos patients according to the dataset described in the study by Wright et al (14). STMN1, stathmin 1.

exhibit any significant increase in fibulin-3 expression (data not shown).
As shown in Fig. 2B, the MeT5A cells exhibited higher protein levels of fibulin-3 following exposure to $\mathrm{FE}$ at the concentrations of 50 and $100 \mu \mathrm{g} / \mathrm{ml}(\mathrm{p}<0.05)$, compared with the controls; however, exposure of the cells to $10 \mu \mathrm{g} / \mathrm{ml}$ of FE did not lead to any significant changes in fibulin-3 protein expression compared with the untreated MeT5A cells.

mRNA fibulin-3 overexpression was detected in the cells exposed to each of the three concentrations of fluoroedenite (Fig. 2C). Similar to the results obtained for the protein levels the cells exposed to the A, B, C and D volcanic particulates did not exhibit any significant increase in mRNA fibulin-3 expression (data not shown).

Computational analysis of stathmin 1. A publically available dataset of 56 lung cancer samples was analyzed for the expression of stathmin 1. This dataset comprised 26 tumor samples from lung cancer patients with a history of exposure to asbestos. The transcript levels of stathmin were significantly higher in the group of tumors derived from patients exposed to asbestos compared with the other group not exposed to asbestos (Fig. 3).

\section{Discussion}

FE, a mineral from the calcic clino-amphibole subgroup, was found in the sputum of subjects from Biancavilla, a city in Eastern Sicily, and in lung specimens from sheep living nearby $(12,13,17)$. In particular, various types of airborne asbestos-like mineral fibers were identified in the volcanic area of Mount Etna and may represent the cause of the increased incidence of mesothelioma and lung cancer and other lung diseases (18). As far back as 1987, the International Agency of Research on Cancer emphasized that the vast majority of asbestos-induced diseases are caused by occupational exposure, as well as non-occupational asbestos exposure $(19,20)$. Starting from in the mid-1970s, the discovery of sites of endemic mesothelioma in some rural areas (Turkey, Greece, Cyprus, Corsica, and more recently, New Caledonia, Sicily, China and California) has provided important information about the carcinogenicity of various mineral fibers $(6,21)$.

In the present study, for the first time, at least to the best of our knowledge, the expression levels of fibulin-3 in normal mesothelial cells following exposure to both FE and other volcanic particulates were analyzed. These data strongly support the notion that fibulin-3 in mesothelial cells is activated following exposure to FE and not following exposure to the other particulates. These results suggest the potential role of fibulin-3 in the development of neoplastic and non-neoplastic diseases of the respiratory tract in subjects exposed to FE (11).

Surprisingly, we also observed that the plasma levels of fibulin-3 were significantly lower in the group of workers exposed to asbestos fibers compared to those previously observed exposed to FE (11). These findings suggest that asbestos disposal workers properly used the personal protective equipment (PPE) according to the current regulations. By contrast, other workers, such as street cleaners should be better equipped to prevent injury caused exposure to FE (11). According to this observation, our in vitro experiments indicated that fibulin-3 was overexpressed in mesothelial cells following exposure to FE and not following exposure to volcanic particulates. These 
data were observed at both the transcript and protein levels. Therefore, we can argue that the detection of high plasma levels of fibulin-3, observed in street cleaners from the Biancavilla area, may be due to FE exposure (11). However, exposure to volcanic particulates did not affect fibulin-3 expression. These data may be in agreement with those of a previous study demonstrating the high incidence of mesotheliomas in the area of Biancavilla associated with exposure to FE (18).

Overall, our data support the notion that the increased levels of fibulin-3 are associated most likely with an inflammatory mechanism caused by exposure to FE (22). Furthermore, these data indicate that the subset of subjects exposed to FE has to be monitored for the development of mesothelioma. Accordingly, it is already known that chronic exposure to asbestos-like fibers may cause chronic inflammation and cancer. Such chronic inflammation is associated with the production of several cytokines and growth factors that may cause cellular proliferation and apoptosis arrest $(9,22)$. On this matter, it has been shown that p27 is downregulated in mesothelial cells following exposure to FE fibers (23). Notably, p27 is considered a tumor suppressor gene due to its function as a regulator of the cell cycle, and in cancers it is often inactivated (24). It has also been demonstrated that low levels of p27 are associated with stathmin upregulation, determining an aggressive phenotype of tumor cells (25). Of note, we have previously demonstrated that stathmin expression is useful for the survival of cancer cells carrying a p53 mutant (26) that may be also involved in the drug resistance mechanisms of hematopoietic cells (27). On this ground, we performed a bioinformatic evaluation to determine whether stathmin is involved in the malignant transformation associated with exposure to asbestos-like fibers. This computational approach showed the overexpression of stathmin in the group of 26 lung cancer patients with a history of asbestos exposure compared with those not exposed to any fibers. According to these data, we can speculate that both fibulin-3 overexpression and stathmin activation may be responsible for the malignant transformation of mesothelial cells following exposure to asbestos-like fibers.

\section{References}

1. Wagner JC, Sleggs CA and Marchand P: Diffuse pleural mesothelioma and asbestos exposure in the North Western Cape Province. Br J Ind Med 17: 260-271, 1960.

2. Boffetta P: Health effects of asbestos exposure in humans: a quantitative assessment. Med Lav 89: 471-480, 1998.

3. International Agency for Research on Cancer: Asbestos (Chrysolite, Amosite, Crocidolite, Tremolite, Actinolite, and Anthophyllite). In: IARC Monographs. Arsenic, Metals, Fibres and Dusts. International Agency for Research on Cancer, Lyon, pp147-167, 2009.

4. Tan C and Treasure T: Mesothelioma: time to take stock. J R Soc Med 98: 455-458, 2005

5. Robinson BW and Lake RA: Advances in malignant mesothelioma. N Engl J Med 353: 1591-1603, 2005.

6. McDonald JC and McDonald AD: The epidemiology of mesothelioma in historical context. Eur Respir J 9: 1932-1942, 1996.

7. Crisstaudo A, Foddis R and Guglielmi G: Methodology and results of an experience of medical surveillance of people previously exposed to asbestos in Tuscany. G Ital Med Lav Ergon 32 (Suppl 4): 385-388, 2010 (In Italian).

8. Marcus PM, Bergstralh EJ, Fagerstrom RM, Williams DE, Fontana R, Taylor WF and Prorok PC: Lung cancer mortality in the Mayo Lung Project: impact of extended follow-up. J Natl Cancer Inst 92: 1308-1316, 2000.
9. Loreto C, Rapisarda V, Carnazza ML, Musumeci G, Valentino M, Fenga $\mathrm{C}$ and Martinez G: Fluoro-edenite fibres induce lung cell apoptosis: an in vivo study. Histol Histopathol 23: 319-326, 2008.

10. Pass HI, Levin SM, Harbut MR, Melamed J, Chiriboga L, Donington J, Huflejt M, Carbone M, Chia D, Goodglick L, et al: Fibulin-3 as a blood and effusion biomarker for pleural mesothelioma. N Engl J Med 367: 1417-1427, 2012.

11. Rapisarda V, Ledda C, Migliore M, Salemi R, Musumeci A, Bracci M, Marconi A, Loreto C and Libra M: FBLN-3 as a biomarker of pleural plaques in workers occupationally exposed to carcinogenic fibers: a pilot study. Future Oncol 11 (Suppl 24): 35-37, 2015.

12. Bruni BM, Pacella A, MazziottiTagliani S, Gianfagna A and Paoletti L: Nature and extent of the exposure to fibrous amphiboles in Biancavilla. Sci Total Environ 370: 9-16, 2006.

13. Putzu MG, Bruno C, Zona A, Massiccio M, Pasetto R, Piolatto PG and Comba P: Fluoro-edenitic fibres in the sputum of subjects from Biancavilla (Sicily): a pilot study. Environ Health 5: 20, 2006.

14. Ledda C, Rapisarda V, Bracci M, Proietti L, Zuccarello M, Fallico R, Fiore M and Ferrante M: Professional exposure to basaltic rock dust: assessment by the Vibrio fischeri ecotoxicological test. J Occup Med Toxicol 8: 23, 2013.

15. Wright CM, Savarimuthu Francis SM, Tan ME, Martins MU, Winterford C, Davidson MR, Duhig EE, Clarke BE, Hayward NK, Yang IA, et al: MS4A1 dysregulation in asbestos-related lung squamous cell carcinoma is due to CD20 stromal lymphocyte expression. PLoS One 7: e34943, 2012.

16. Polesel J, Franceschi S, Talamini R, Negri E, Barzan L, Montella M, Libra M, Vaccher E, Franchin G, La Vecchia C and Serraino D: Tobacco smoking, alcohol drinking, and the risk of different histological types of nasopharyngeal cancer in a low-risk population. Oral Oncol 47: 541-545, 2011.

17. De Nardo P: More attention to veterinarian epidemiologists. Epidemiol Prev 28: 194, 2004 (In Italian).

18. Paoletti L, Batisti D, Bruno C, Di Paola M, Gianfagna A, Mastrantonio M, Nesti M and Comba P: Unusually high incidence of malignant pleural mesothelioma in a town of eastern Sicily: an epidemiological and environmental study. Arch Environ Health 55: 392-398, 2000.

19. International Agency for Research on Cancer: IARC Monographs on the evaluation of carcinogenic risks to humans. Supplement 7. Vol 1-42. IARC Press, Lyon, 1987.

20. Committee on Asbestos: Selected Health Effects; Board on Population Health and Public Health Practices; Institute of Medicine: Asbestos: Selected Cancers. The National Academies Press, Washington, DC, 2006.

21. Goldberg M and Luce D: The health impact of nonoccupational exposure to asbestos: what do we know? Eur J Cancer Prev 18: 489-503, 2009.

22. Cardile V, Lombardo L, Belluso E, Panico A, Renis M, Gianfagna A and Balazy M: Fluoro-edenite fibers induce expression of Hsp70 and inflammatory response. Int J Environ Res Public Health 4: 195-202, 2007.

23. Musumeci G, Cardile V, Fenga C, Caggia S and Loreto C: Mineral fibre toxicity: Expression of retinoblastoma $(\mathrm{Rb})$ and phospho-retinoblastoma (pRb) protein in alveolar epithelial and mesothelial cell lines exposed to fluoro-edenite fibres. Cell Biol Toxicol 27: 217-225, 2011.

24. Chu IM, Hengst L and Slingerland JM: The Cdk inhibitor p27 in human cancer: prognostic potential and relevance to anticancer therapy. Nat Rev Cancer 8: 253-267, 2008.

25. Baldassarre G, Belletti B, Nicoloso MS, Schiappacassi M, Vecchione A, Spessotto P, Morrione A, Canzonieri V and Colombatti A: p27(Kip1)-stathmin interaction influences sarcoma cell migration and invasion. Cancer Cell 7: 51-63, 2005.

26. Sonego M, Schiappacassi M, Lovisa S, Dall'Acqua A, Bagnoli M, Lovat F, Libra M, D'Andrea S, Canzonieri V, Militello L, et al: Stathmin regulates mutant p53 stability and transcriptional activity in ovarian cancer. EMBO Mol Med 5: 707-722, 2013.

27. McCubrey JA, Abrams SL, Ligresti G, Misaghian N, Wong EW, Steelman LS, Bäsecke J, Troppmair J, Libra M, Nicoletti F, et al: Involvement of p53 and Raf/MEK/ERK pathways in hematopoietic drug resistance. Leukemia 22: 2080-2090, 2008. 